\title{
Query Details
}

Back to Main Page

1. Please confirm whether the author names are presented accurately and in the correct sequence (given name, middle name/initial, family name). Author 2: Given name [Muhammad Arfat], Last name [Yameen]; Author 3: Given name [Hafiza Fakhera], Last name [Ikram]; Author 5: Given name [Aqif Anwar], Last name [Chaudhry]; Author 6: Given name [Ihtesham], Last name [ur Rehman]. Also, kindly confirm whether the details in the metadata are correct.

yes they are correct

2. Please check and confirm the volume ID and page number are correctly identified for the reference Justus et al. (2014).

please modify this reference as:

Justus, C. R., Leffler, N., Ruiz-Echevarria, M., Yang, L. V. In vitro Cell Migration and Invasion Assays. J. Vis. Exp. (88), e51046, doi:10.3791/51046 (2014).

\section{Fabrication of dual drug loaded} bilayered chitosan based composite scaffolds as osteochondral substitutes and evaluation of in vitro cell response using the $\mathrm{MC}_{3} \mathrm{~T} 3$ preosteoblast cell line

Muhammad Samie, 1,2

Muhammad Arfat Yameen,

Emailarfatyameen@yahoo.com

Hafiza Fakhera Ikram, 
Haffsah Iqbal, 1

Aqif Anwar Chaudhry,

Ihtesham ur Rehman, 3

Ather Farooq Khan,

Email atherfarooq@cuilahore.edu.pk

1 Interdisciplinary Research Centre in Biomedical Materials, COMSATS University Islamabad, Lahore campus, Islamabad, 54000 Pakistan

2 Department of Pharmacy, COMSATS University Islamabad, Abbottabad campus, Islamabad, 22060 Pakistan

3 Bioengineering, Engineering Department, Lancaster

University, Lancaster, UK

Received: 4 June 2019 / Accepted: 4 December 2019

\section{Abstract}

Osteochondral defects are relatively common in weight-bearing joints of the lower extremities and require multiple approaches of treatment. This work is focused on designing three-dimensional (3D) bilayered scaffolds fully integrating a top chitosan/hydroxypropylmethyl cellulose layer (CS/HPMC) mimicking cartilage and a bottom chitosan/hydroxypropylmethyl cellulose/nano-hydroxyapatite layer (CS/HPMC/nHAp) imitating bone for the treatment of osteochondral defects prepared by freeze drying. Additionally, an anti-inflammatory drug (in the bottom layer) and an antibiotic drug (in the top layer) are incorporated in the form of microspheres and nanofibers, respectively, into these scaffolds to diminish/prevent post-surgical inflammation/infection through sustained release of the drugs. The scaffolds were characterized by a variety of techniques. FT-IR analysis 
confirmed that there is no/weak interactions between the components, SEM images showed that both layers of the scaffolds have homogenous pore distribution, and scaffolds exhibited reproducible swelling and degradation behavior. Drug release was shown to take place over a period of 14 days in PBS. The scaffolds supported the growth and proliferation of MC3T3 pre-osteoblast cells in vitro and have potential for use in vivo application in the future.

AQ1

\section{Keywords}

Cartilage

Osteochondral defect

Drug release

Bilayered scaffold

Freeze drying

Abbreviations

CS Chitosan

TCN Triamcinolone acetonide

TCN/MS Triamcinolone acetonide loaded microspheres

CFX Cefixime trihydrate

CFX/NF Cefixime trihydrate loaded nanofibers

MW Molecular weight

HPMC Hydroxypropylmethyl cellulose

nHAp Nano hydroxyapatite

EDTA Ethylenediaminetetraacetic acid

IRCBM Interdisciplinary Research Centre in Biomedical Materials

$\mathrm{CaP}$ Calcium Phosphate

OPF Oligo (polyethylene glycol) fumarate

Electronic supplementary material 
The online version of this article (https://doi.org/10.1007/s10570-01902915-x) contains supplementary material, which is available to authorized users.

\section{Introduction}

Osteochondral defects arising in hard tissues as a result of repeated trauma or diseases involving articular cartilage as well as underlying calcified subchondral tissue eventually lead to joint destruction, which remain an important clinical challenge for researchers (Martin et al. 2007;

Levingstone et al. 2014). Cartilage defects are normally irreversible due to their poor intrinsic healing ability and progressive deterioration if not properly treated (Seo et al. 2011). The treatment options of articular cartilage include either conservative treatment or operative treatment (Falah et al. 2010). Conservative treatment is concerned with the reduction of symptoms rather than healing, whereas operative treatment includes techniques, such as, (1) autologous chondrocyte implantation, (2) bone marrow stimulation and (3) autografting/allografting (Bohaček et al. 2015). However, these approaches are still not completely successful due to limited accessibility, donor site morbidity, associated immune response and disease (Nukavarapu and Dorcemus 2013; García-Gareta et al. 2015). Tissue engineering can be employed to address these issues, providing alternate ways to regenerate tissues and aid recovery using natural and synthetic biomaterial-based bioresorbable tissue scaffolds (GhasemiMobarakeh et al. 2008).

Generally, two types of strategies are adopted in tissue engineering i.e. preparation of pristine scaffolds (Gille et al. 2013) or those loaded with growth factors and/or stem cells to be implanted during the surgical procedure (Gobbi et al. 2014). Efforts to reconstruct articular defects originally focused on the repair of cartilage layers without consideration of the lower subchondral tissue with limited success (Huey et al. 2012). Subsequent studies of the structure of osteochondral tissues inspired the development of multilayered scaffolds for the treatment of osteochondral defects (Levingstone et al. 2014). However, to fabricate a composite 
scaffold for osteochondral defects with properties similar to that of articular cartilage is challenging (Doran 2015). The main hurdle associated with the fabrication of multilayered scaffolds is achieving a robust interface between the layers (Yang and Temenoff 2009). Several attempts have been reported regarding the design of bilayered scaffolds for osteochondral defects, whereas some (e.g. Trufit ${ }^{\circledR}$ and MaioRegen ${ }^{\circledR}$ ) have been clinically translated (Kon et al. 2011). Tissue scaffolds are commonly designed to have interconnectivity within their porous structures and mechanical strengths similar to the native tissue with a controlled degradation rate that matches the rate of tissue regeneration. In comparison to this, for in vivo osteochondral scaffolds, it is desirable for the cartilage layer to degrade at a faster rate than the bone layer to allow rapid cell migration (Sridharan et al. 2016). Bilayered scaffolds composed of silk and silk-nano CaP for osteochondral regeneration were produced and evaluated for their in vitro and in vivo behavior (Yan et al. 2014; Yan et al. 2015). Lu et al. (2014) also synthesized bilayered OPF scaffolds for osteochondral defects incorporating dual growth factor loaded gelatin microparticles. Our group prepared robust CS/HPMC/nHAp scaffolds for trabecular (Khan et al. 2015) and alveolar (Iqbal et al. 2017) bone substitutes, and based on the outcomes we have produced bilayer scaffolds comprising CS/HPMC on the top layer and CS/HPMC/nHAp on the bottom layer for use as an osteochondral substitute.

Hydrophilic polymer-based materials swell in water (without dissolving, provided that chemical or physical crosslinks exist among the macromolecular chains) (Sannino et al. 2009). From a clinical perspective, common problems arising at the site of osteochondral defects are inflammation and deterioration of the injury due to infections (Chen et al. 2017). To tackle the issue a common steroidal injection of TCN is administered along with some antibiotic drugs therefore, we incorporated TCN and CFX separately, and as TCN/MS and CFX/NF in the bottom and top layers, respectively. A layer by layer addition method (known as the iterative layering technique) developed by Levingstone et al. (2014) was adopted to fuse both layers which result in a uniform interface. 
Polysaccharide based polymers like HPMC, and chitosan are commonly used in drug delivery applications whereas chitosan is used in tissue engineering as well. This study aims to design bilayered scaffolds with a degree of spatially controlled drug release using natural biomaterials through simple freeze-drying technique and assess their in vitro behavior under static conditions. It was hypothesized that the presence of both methoxy and hydroxypropyl groups in HPMC will increase the crosslinking between HPMC and chitosan that will subsequently prolong the drug release from these scaffolds (Iqbal et al. 2017). Physical and chemical characterization of the scaffolds was carried out with SEM and FT-IR respectively. Additionally, the drug release and cytocompatibility of both layers were evaluated by studying cell adhesion, infiltration and viability using mouse MC3T3 pre-osteoblast cells in vitro.

\section{Materials and methods}

\section{Materials}

Chitosan (MW: 26,200 \& degree of deacetylation: 90\%) was Purchased from Mian Scientific and refined locally at the IRCBM COMSATS University Islamabad, Lahore campus. nHAp (sintering grade) was received from Plasma Biotal Ltd, UK. Hydroxypropyl methyl cellulose (HPMC; molar mass: $4.2 \times 10^{8} \mathrm{~g} / \mathrm{mol}$; methoxy contents of $28-30 \%$, hydroxypropyl contents of 7-12\% and degree of substitution: 0.7 ) was purchased from BDH, UK. Triamcinolone Acetonide (purity $=98.23 \%$ by high performance liquid chromatography) and Cefixime trihydrate were received as gift samples from Gean pharmaceuticals (Sheikhupura road Lahore Pakistan) and Al Sayyed Pharma Hattar, Pakistan respectively. Dichloromethane (DCM; $\mathrm{CH}_{2} \mathrm{Cl}_{2}$ ) and acetic acid were purchased from Daejung, Korea. Ethanol $\left(\mathrm{CH}_{3} \mathrm{CH}_{2} \mathrm{OH}\right)$ was purchased from Merck Germany. Poly( $\varepsilon$-caprolactone) MW 80,000, Phosphate buffered saline tablets (PBS; 0.1 M, pH 7.4), Paraformaldehyde (PFA), Propidium Iodide (PI) $>94.0 \%$ (HPLC grade) and 4',6-Diamidino-2-Phenylindole Dihydrochloride (DAPI) $\geq 98 \%$ (HPLC grade) were purchased from Sigma-Aldrich, Germany, Calcein, AM (MW: 994.86) was purchased from 
AAT Bioquest. Minimum essential medium ( $\alpha$-MEM), trypsin-EDTA and cell culture grade PBS were procured from Gibco, Life Technologies, USA. 10\% Foetal Bovine Serum and 1\% penicillin/streptomycin were purchased from Caisson, USA. MC3T3 Preosteoblast cell line used was from American type culture collection with ATCC \# CRL-2593TM. All chemicals were used as received.

\section{Fabrication of drug loaded bilayered CS/HPMC/nHAp composite scaffolds}

Bilayer scaffolds incorporating CS/HPMC/nHAp were prepared by the freeze drying method described in our previous protocol (Iqbal et al. 2017). Firstly, Chitosan 33\% weight ratio was dissolved in $2 \%$ acetic acid and the solution was stirred gently at room temperature for $4-6 \mathrm{~h}$. Then, the nHAp powder was added and the mixture was ultrasonicated to disperse the nHAp completely. Afterward, HPMC was added alone and/or with TCN in the form of powder and microspheres (TCN loaded PCL microspheres prepared previously) separately with continuous stirring for 30 min to carry out crosslinking. The second layer was made in the same manner without the addition of nHAp whereas TCN was replaced with CFX powder and nanofibers (cefixime loaded PCL nanofibers prepared previously). Finally, the solution was poured into polystyrene molds and frozen overnight at $-40{ }^{\circ} \mathrm{C}$. Both layers were combined through a novel "iterative layering" technique. The frozen layers were lyophilized for $48 \mathrm{~h}$ using a freeze dryer and the CS/HPMC/nHAp bilayered composite scaffolds were obtained. The control composite scaffolds were fabricated using the same preparation method without the addition of drugs. The composition of all formulations is given in the Table 1.

\section{Table 1}

Composition of different formulations on $\mathrm{wt} \%$ basis

\begin{tabular}{|l|l|l|l|l|l|l|l|}
\hline Formulation & Code & $\begin{array}{l}\text { Chitosan } \\
(\mathbf{\%})\end{array}$ & $\begin{array}{l}\text { HPMC } \\
(\mathbf{\%})\end{array}$ & $\begin{array}{l}\text { nHAp } \\
\mathbf{( \% )}\end{array}$ & $\begin{array}{l}\text { TCN } \\
(\mathbf{\%})\end{array}$ & $\begin{array}{l}\text { CFX } \\
(\mathbf{\%})\end{array}$ & $\begin{array}{l}\text { PCL } \\
(\mathbf{\%})\end{array}$ \\
\hline $\begin{array}{l}\text { Bottom } \\
\text { control } \\
\text { a These codes are used in the main text to represent their respective formulations }\end{array}$ \\
\hline
\end{tabular}




\begin{tabular}{|l|l|l|l|l|l|l|l|}
\hline Formulation & Code & $\begin{array}{l}\text { Chitosan } \\
(\mathbf{\%})\end{array}$ & $\begin{array}{l}\text { HPMC } \\
\mathbf{( \% )}\end{array}$ & $\begin{array}{l}\text { nHAp } \\
\mathbf{( \% )}\end{array}$ & $\begin{array}{l}\text { TCN } \\
(\mathbf{\%})\end{array}$ & $\begin{array}{l}\text { CFX } \\
(\mathbf{\%})\end{array}$ & $\begin{array}{l}\text { PCL } \\
(\mathbf{\%})\end{array}$ \\
\hline Top control & ${ }^{\mathrm{a}} \mathrm{C}_{\mathrm{o}}$ & 62 & 38 & - & - & - & - \\
\hline $\begin{array}{l}\text { TCN in } \\
\text { bottom }\end{array}$ & ${ }^{\mathrm{a}} \mathrm{B}_{1}$ & 30 & 25 & 40 & 5 & - & - \\
\hline CFX in top & ${ }^{\mathrm{a}} \mathrm{C}_{1}$ & 60 & 35 & - & - & 5 & - \\
\hline $\begin{array}{l}\text { TCN/MS in } \\
\text { bottom }\end{array}$ & ${ }^{a} \mathrm{~B}_{2}$ & 30 & 20 & 27 & 5 & - & 18 \\
\hline $\begin{array}{l}\text { CFX/NF in } \\
\text { top }\end{array}$ & ${ }^{\mathrm{a}} \mathrm{C}_{2}$ & 50 & 32 & - & - & 5 & 13 \\
\hline
\end{tabular}

${ }^{a}$ These codes are used in the main text to represent their respective formulations

\section{Characterization of drug loaded bilayered CS/HPMC/nHAp composite scaffolds}

Data about characterizations like Fourier transform infrared spectroscopy, degradation behavior, porosity and swelling studies is provided separately in the supplementary information section.

\section{Scanning electron microscopy}

The morphology of the obtained scaffolds was examined by scanning electron microscopy (SEM, VEGA3, Tescan). The samples were first cut into rectangular pieces using a fine sterilized razor blade and fixed on metal stubs. After sputter coating with gold under vacuum the samples were placed in the chamber for microstructural analysis. The obtained images were further processed using ImageJ software.

\section{Test of mechanical properties}

The compressive strength of the fabricated scaffolds is measured at room temperature using Electrodynamic fatigue testing machine (LFV-E $1.5 \mathrm{kN}$ ) according to the guidelines set in ASTM D5024-95a. The samples are cut into longitudinal shapes of $(5 \times 3 \times 3 \mathrm{~mm}$ dimensions $)$ and held in place between the two jigs. The compression force was applied at a strain rate of 
$1 \times 10^{-3} / \mathrm{s}$ and crosshead speed between 0.2 and $0.35 \mathrm{~mm} / \mathrm{min}$ up to $25 \%$ deformation. The elastic modulus and universal compressive strength is measured in triplicate for all samples and average value is calculated.

\section{In vitro drug release studies}

The drug release from the fabricated scaffolds is studied in PBS (pH 7.4). For this purpose, $5 \mathrm{ml}$ of sterile PBS is taken in $10 \mathrm{ml}$ tubes. The scaffolds are cut into discs of equal weight and immersed in the PBS solution. The tubes are kept at $37 \pm 0.5{ }^{\circ} \mathrm{C}$ in a shaking water bath at $40 \mathrm{rpm}$ and after stipulated time intervals a $1 \mathrm{ml}$ aliquot is withdrawn. The samples are analyzed for the quantification of both TCN and CFX through UV-visible spectrophotometer at a wavelength of $236 \mathrm{~nm}$ and $287 \mathrm{~nm}$ respectively. Every time an equal amount of pre-warmed fresh PBS is added to the tubes in order to keep the volume of dissolution medium constant. The calibration curves of TCN and CFX are plotted with known concentrations in PBS-Methanol with a $(1: 1)$ volume ratio and cumulative percent drug release with respect to time was calculated.

\section{Drug release kinetics}

To study the release mechanism from the drug loaded scaffolds the drug release data was fitted into different kinetic models including zero order, first order, Higuchi model, Hixon-Crowell model and Korsmeyer Peppas model. The kinetic models and their equations are as follows

$$
\text { Zero order rate equation } \mathrm{Q}=\mathrm{Kt}
$$

where "Q" is amount of un-dissolved drug at time t, " $\mathrm{K}$ " is zero order rate constant and " $\mathrm{t}$ " is the time.

First order rate equation $\log C=\log C_{o}-K t / 2.303$

where " $\mathrm{C}_{\mathrm{o}}$ " is the initial concentration of drug, " $\mathrm{K}$ " is first order constant and " $t$ " is the time.

Higuchi model equation $\mathrm{Q}=\mathrm{K} 3 \sqrt{ } \mathrm{t}$ 
where "Q" represents the percent of drug released in time $t$, " $\mathrm{K}$ " is Higuchi's constant and " $\mathrm{t}$ " is the time.

$$
\text { Hixon }\{-\} \text { Crowell model } \mathrm{A}_{\mathrm{o}}^{1 / 3}-\mathrm{At}^{1 / 3}=\mathrm{K}_{\mathrm{HC}} \mathrm{t}
$$

where " $A_{o}$ " is the initial amount of the drug, " $A_{t}$ " is the amount of drug released in time $\mathrm{t}$, " $\mathrm{K}_{\mathrm{HC}}$ " is the Hixson-Crowell rate constant and " $\mathrm{t}$ " is the time.

Korsmeyer Peppas Equation $\mathrm{Mt} / \mathrm{M} \alpha=\mathrm{K}_{\mathrm{kp}} \mathrm{t}^{\mathrm{n}}$

where "Mt/M $\alpha$ " is the fraction of drug released at time $t$, " $\mathrm{K}_{\mathrm{kp}}$ " is the rate constant incorporating the properties of macromolecular polymeric system and drug, " $n$ " is the release exponent used to characterize the transport mechanism and " $\mathrm{t}$ " is the time.

\section{Cell culture}

The mouse MC3T3-E1 pre-osteoblast cell lines were purchased from American type culture collection (ATCC \# CRL-2593TM). The cells were cultured in primary medium containing low glucose Minimum essential medium (Gibco, USA) supplemented with 10\% foetal bovine serum and $1 \%$ penicillin/streptomycin (Caisson, USA). The cells were passaged using trypsin/EDTA and cells from $\mathrm{P}=5$ are being used in the study and incubated at $37{ }^{\circ} \mathrm{C}$ in a humidified incubator with $5 \% \mathrm{CO}_{2}$ supply. All the experiments are performed in triplicate.

\section{Cell attachment assay}

For cell attachment the cells were re-suspended in culture medium after trypsinization and seeded on to the scaffolds (pre-sterilized in UV light) at a concentration of $2 \times 10^{4}$ cells per well in a 24 well plate. The cells were allowed to fully attach at the surface of scaffolds and proliferate in a $\mathrm{CO}_{2}$ incubator. After 3 days of incubation the cells are fixed by dipping in $4 \%$ PFA (Para formaldehyde) solution for $30 \mathrm{~min}$. The samples were washed with PBS and dehydrated using a serial dilution of ethanol solution i.e. 
$50 \%, 60 \%, 70 \%, 80 \%, 90 \%$ and $100 \%$ (15 min each). The samples were then analyzed by SEM.

\section{Cell migration assay}

For cell migration assay an established protocol was used as described elsewhere (Justus et al. 2014). Briefly equal number of cells were plated in a 6 well plate and allowed to become confluent. Under aseptic conditions a vertical scratch was created gently in the cell monolayer using a sterile micropipette tip. The culture media and cell debris were aspirated carefully and replaced with fresh medium through the sides of the well wall to cover the bottom of the plate. An initial picture of the wound was taken after the scratch was made and the plate was incubated in $\mathrm{CO}_{2}$ incubator for different time intervals. After every time interval the plates were removed from incubator, placed under an inverted microscope and picture was taken to check for gap closure. A graph was then plotted between the gap closure and time.

\section{Cell viability and proliferation assay}

\section{Alamar blue assay}

For quantitative determination of cell viability alamar blue assay was performed. For this purpose, exponentially growing cells were used. The live cells were estimated with trypan blue staining and counted using hemocytometer. The sample discs were sterilized using 70\% ethanol and UV light before starting the assay and placed in a 24 well plate. The cells were seeded at a density of $2 \times 10^{4}$ cells per well in triplicate and incubated for 2 and 8 days in a humidified $5 \% \mathrm{CO}_{2}$ incubator at $37{ }^{\circ} \mathrm{C}$. After each time point, alamar blue working solution was made and added to the individual wells $(200 \mu \mathrm{l} / 2 \mathrm{ml})$. Incubated for $4-5 \mathrm{~h}$ in a $\mathrm{CO}_{2}$ incubator and measured the absorbance at 550 and $620 \mathrm{~nm}$ using a microplate reader (Biorad PR4100 absorbance Microplate reader). Cells without the addition of sample were used as positive controls.

Live/dead assay and nuclei staining 
For live and dead cells viability assay, equal number of cells were seeded on each sample in a 24 well plate and incubated for 9 days in $5 \% \mathrm{CO}_{2}$ incubator. After the specified period, the cells proliferation medium was aspirated from the wells and were incubated in dark with $3 \mu \mathrm{M}$ Calcein AM and 2.5-5 $\mu \mathrm{M}$ propidium iodide in DPBS (400 $\mu 1$ for 24 well plate) for $30 \mathrm{~min}$. Images were recorded immediately using fluorescent microscope under green and red filters. The samples were then washed with PBS and again stained with DAPI solution which enables the nucleus to retain the blue dye. The scaffolds were observed under fluorescent microscope where live cells showed blue fluorescence upon exposure to the fluorescence light. The images were further analyzed using ImageJ software.

\section{Statistical analysis}

The data is presented as a mean \pm standard deviation. The criteria for statistical significance is set with a probability value of $p<0.05$.

\section{Results and discussion}

\section{Scanning electron microscopy}

SEM images (e.g. in Fig. 1a, b) show a clear interface between the top and bottom layers. This interface clearly distinguishes between the two layers which are supposed to release two different drugs and support the growth of bone and cartilage forming cells due to their bioactive nature. The porosity at $100 \times$ magnification shows that cartilage control $\left(\mathrm{C}_{\mathrm{o}}\right)$ is more porous than bone control $\left(\mathrm{B}_{\mathrm{o}}\right)$ as shown in Fig. 1c, $\mathrm{d}$ which was further confirmed by measuring the porosity (see in the supplementary data sheet). This difference in porosity is caused by the presence of nHAp crystals in $\mathrm{B}_{0}$. The pore size in $\mathrm{B}_{\mathrm{o}}$ is also smaller than $\mathrm{C}_{\mathrm{o}}$ which is attributed to the existence of a strong interactions between chitosan and nHAp. The pore size also effects the mechanical properties, i.e. the denser the scaffold the more strength it exhibits as compared to porous ones, however, small pore sizes and denser walls limit cell migration and perfusion inside 3D scaffolds (Whited et al. 2011). A uniform distribution of nHAp crystals was observed as shown by arrow heads in $B_{o}(E)$ while complete absence 
in the $\mathrm{C}_{\mathrm{o}}(\mathrm{F})$. This indicates that no leaching of the nHAp from bottom to top layer happened during the freeze drying. The EDX analysis also confirmed it where the peaks of both calcium and phosphate appears in $\mathrm{B}_{\mathrm{o}}$ while absent in $\mathrm{C}_{\mathrm{o}}$ as shown in Fig. 2. The presence of microspheres in $\mathrm{B}_{2}$ layer is also visible inside the pores pointed with yellow arrow heads Fig. 1g and were added for providing prolonged release of the drug however their presence also affected the strength and degradation of the scaffolds. The distribution of microspheres inside the pores was good in case of in situ loading rather than the post seeding method. The smaller size of microspheres $(2-100 \mu \mathrm{m})$ than the pore size seems to be responsible for the even distribution without affecting morphology. The nanofibers are also embedded and distributed uniformly throughout the pore walls of $\mathrm{C}_{2}$ layer as can be seen in the cross-sectional examination at a higher resolution i.e. $500 \times$ Fig. 1 h. These results indicate that blending $\mathrm{CS} / \mathrm{HPMC} / \mathrm{nHAp}$ in different weight ratios to fabricate porous 3D bilayer composite scaffolds is accomplishable/realistic and in situ loading of microspheres and nanofibers didn't affected the surface morphology of the scaffolds.

\section{Fig. 1}

SEM images of the bilayered scaffolds showing two distinct layers separated by dotted lines $(\mathbf{a}, \mathbf{b})$, detailed SEM analysis of $\mathrm{B}_{\mathrm{o}}$ and $\mathrm{C}_{\mathrm{o}}$ layers taken at $\times 100$ magnification as shown in $\mathbf{c}$ and $\mathbf{d}$. The presence of nHAp crystals on the surface of pore walls at $\times 500$ magnification in $B_{1}$ layer while absence in $\mathrm{C}_{1}$ layer as shown in $\mathbf{e}$ and $\mathbf{f}$. Clearly visible microspheres inside the pores of $\mathrm{B}_{2}$ layer and nanofibers embedded in pore walls of $\mathrm{C}_{2}$ layer can also be seen at the same magnification i.e. $\times 500$ as shown in $\mathbf{g}$ and $\mathbf{h}$ respectively 

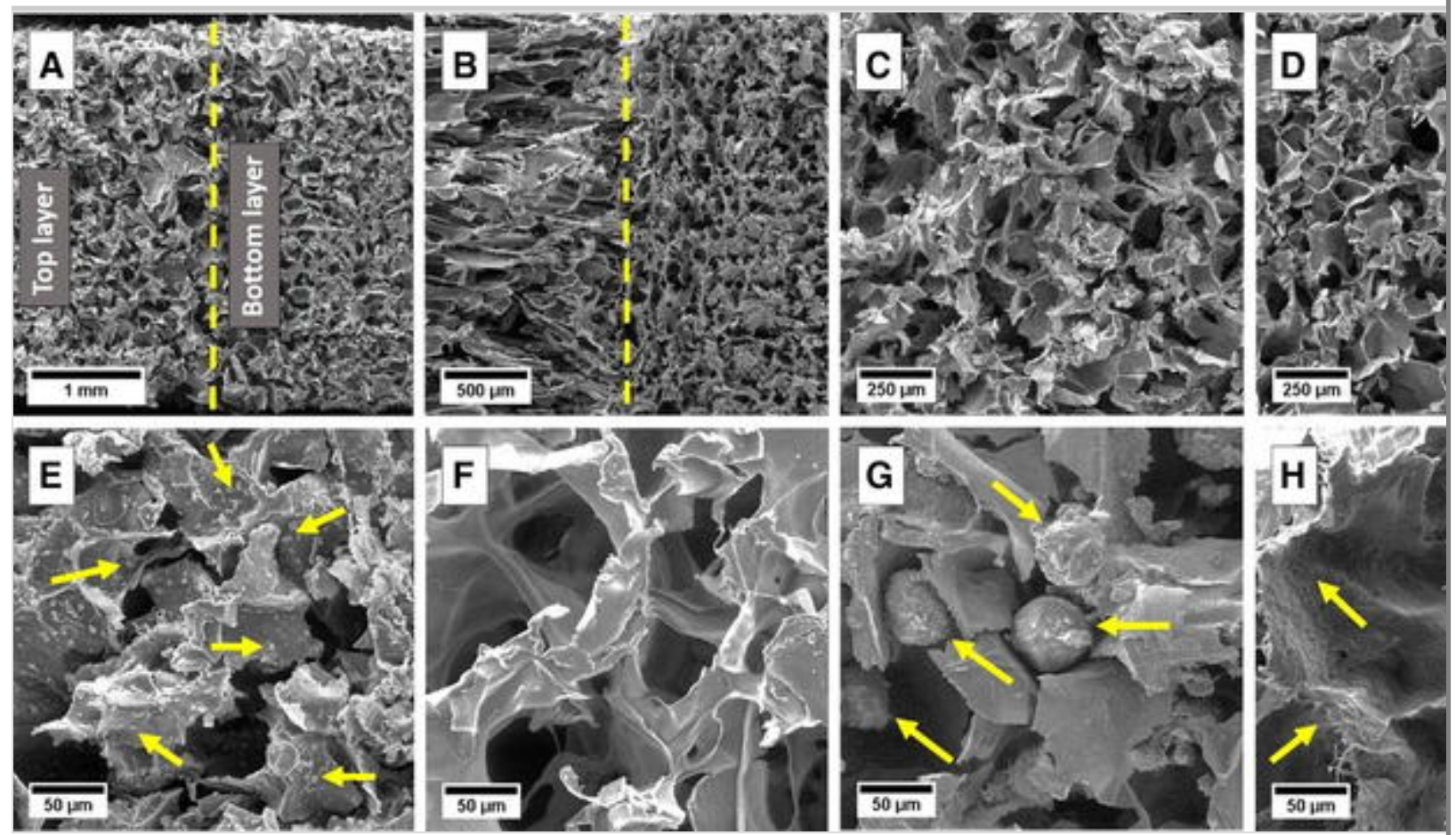

\section{Fig. 2}

EDX analysis of $\mathrm{B}_{0}$ and $\mathrm{C}_{0}$ showing the peaks of $\mathrm{Ca}^{++}$and $\mathrm{PO}_{4}^{-}$in the bottom layer while only $\mathrm{C}$ and $\mathrm{O}$ peaks are visible in the top layer 

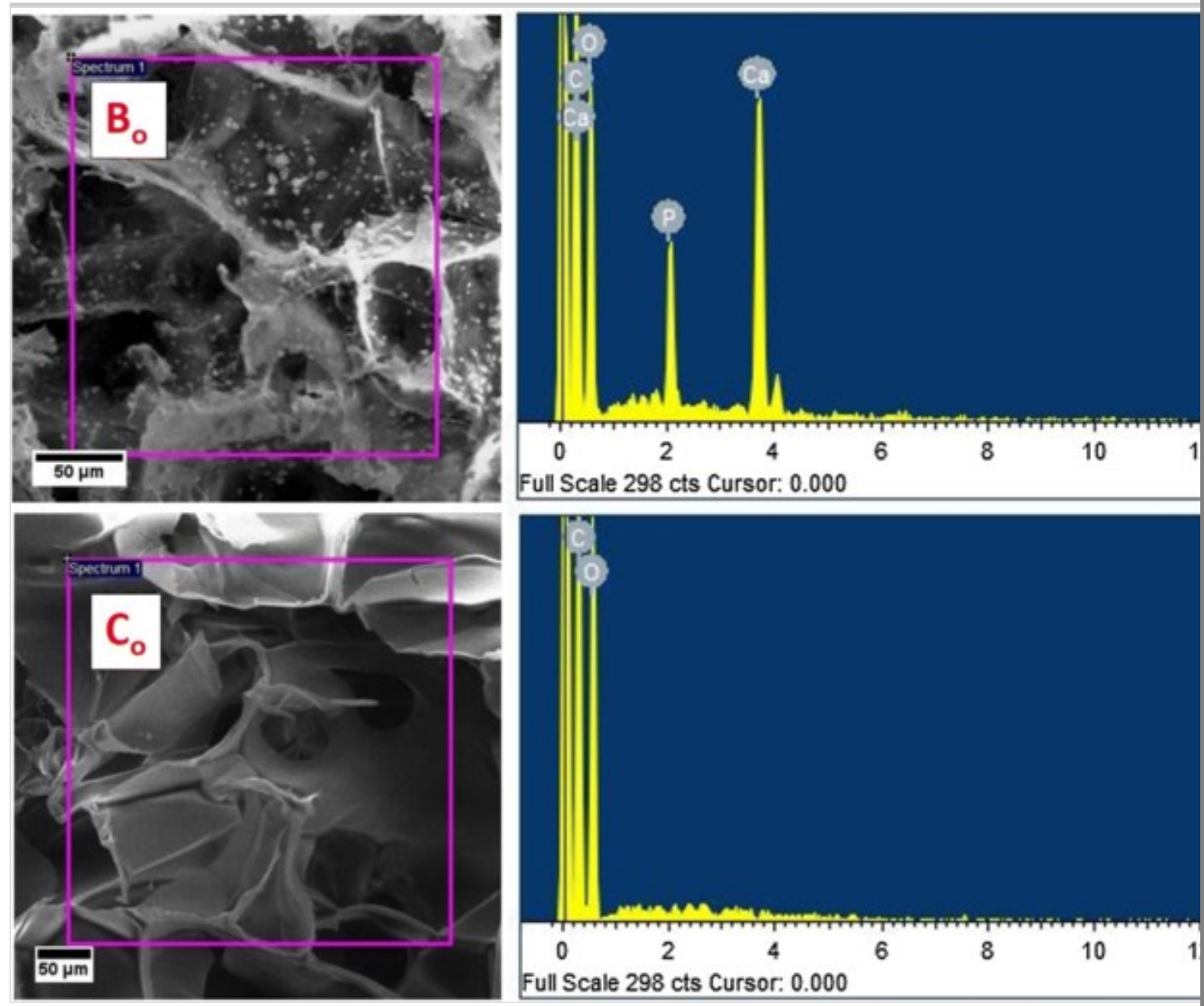

\section{Test of mechanical properties}

The mechanical strength is a very important parameter in hard tissue engineering especially in weight bearing areas. Studies have shown that decreasing wall thickness will result in enhanced interconnectivity (Robinson et al. 2014). Studies also suggest that reducing porosity and increasing wall thickness can increase compressive modulus but at the same time reduces cell infiltration (Bouville et al. 2014; Ruiz-Cantu et al. 2016). An ideal scaffold for bone regeneration should have optimal porosity and needs to be strong enough to bear the load during the healing period (Polo-Corrales et al. 2014). The results of compressive strength of the fabricated scaffolds with different compositions are shown in Fig. 3. It is evident from the results that $\mathrm{B}_{\mathrm{o}}$ and $\mathrm{B}_{1}$ didn't shown much difference in 
the elastic modulus i.e. $3.1674 \pm 0.8244 \mathrm{MPa}$ and $3.1105 \pm 0.8295 \mathrm{MPa}$, however, there is a marked difference in their compressive strengths i.e. $0.2078 \pm 0.0224 \mathrm{MPa}$ and $0.2665 \pm 0.0235 \mathrm{MPa}$, respectively. The same kind of relationship was previously observed by Uswatta et al. (2016) and Beşkardeş et al. (2015). When these results are compared with $\mathrm{B}_{2}$, an increase in the elastic modulus was seen $(3.6950 \pm 1.7460 \mathrm{MPa})$ while the compressive strength remained similar to $\mathrm{B}_{1}(0.2614 \pm 0.0522 \mathrm{MPa})$. This increase in elastic modulus is attributed to the presence of PCL microspheres within the pores which exhibited some plasticizing properties. On the other hand, the formulation $\mathrm{C}_{\mathrm{o}}$ and $\mathrm{C}_{1}$ also exhibited a similar behavior to $\mathrm{B}_{0}$ and $\mathrm{B}_{1}$ in case of elastic modulus, i.e. $0.7643 \pm$ $0.6436 \mathrm{MPa}$ and $0.7558 \pm 0.1764 \mathrm{MPa}$, while a contrast to the previous result is seen in case of mechanical strength, i.e. $0.0754 \pm 0.0412 \mathrm{MPa}$ and $0.0865 \pm 0.0051 \mathrm{MPa}$, respectively. This is because of the absence of nHAp in top layer and also because of the similar micromeritic properties of chitosan and CFX. The formulation $\mathrm{C}_{2}$ displayed increased elastic modulus $(0.9527 \pm 0.3148 \mathrm{MPa})$ and also compressive strength $(0.1159 \pm$ $0.0319 \mathrm{MPa}$ ) which is because of the plastic nature of PCL nanofibers embedded in the pore walls of the top layer of scaffold. The mechanical strength of these scaffolds is because of the existence of a strong chemical crosslinking between chitosan and HPMC whereas in contrast the physical interaction results in reduced strength and stiffness which was previously reported by (Ghasemi-Mobarakeh et al. 2015). It was also reported that increasing the degree of crosslinking results in promotion of bone regeneration through stem cells.

\section{Fig. 3}

Elastic modulus (a) and ultimate compressive strength (b) of the developed scaffolds $(n=3)$ 


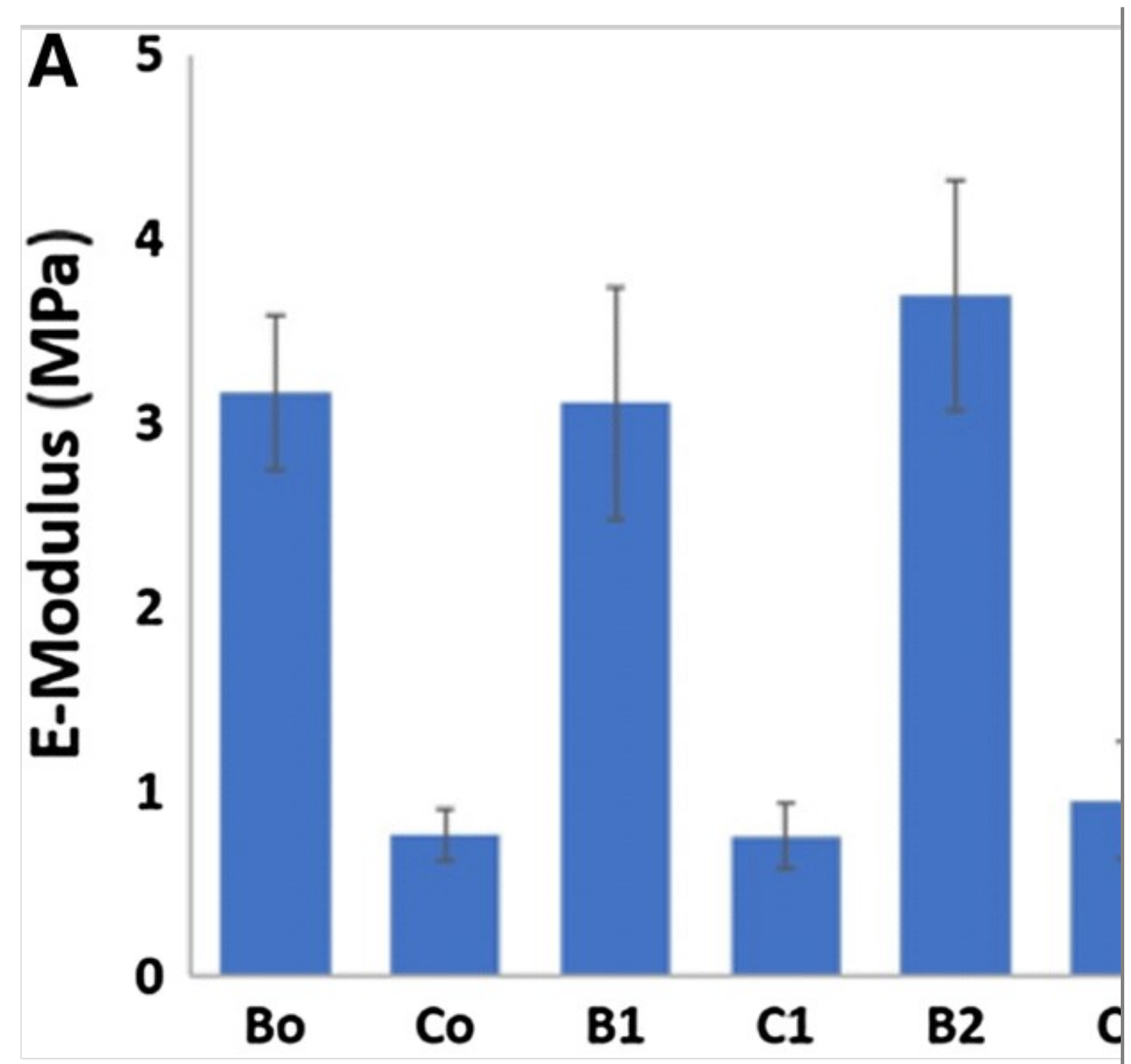

\section{In vitro drug release studies}

The drug release data is obtained for both drugs separately. For this purpose, the standard curves are initially plotted for both drugs and percent drug release data is calculated. From the release data shown in Fig. 4 (see also Table S1 in supplementary data sheet), it can be assessed that both drugs are released in a sustained manner from their respective formulations. $\mathrm{B}_{2}$ and $\mathrm{C}_{2}$ were able to prolong the release up to 14 days than $B_{1}$ and $C_{1}$ which released their maximum drug load at day 7 . By considering the release data of $\mathrm{B}_{1}$ the drug release looks faster at initial 
time points and within $24 \mathrm{~h}$ almost $40 \%$ of drug is released. By comparing this data with $\mathrm{C}_{1}$ a little bit slow release pattern is noted and at the end of $24 \mathrm{~h}$ only $23 \%$ of drug is released which is due to the presence of high HPMC contents in the top layer than the bottom layer. In both these formulations a sudden increase in drug release is also noted between 48 and $72 \mathrm{~h}$ which seems to be due to some loosely bound drug that was lost by surface erosion started. The $\mathrm{B}_{1}$ released $95.37 \%$ and $\mathrm{C}_{1}$ released $85.90 \%$ of drug in 7 days. Whereas $\mathrm{B}_{2}$ released the drug in a sustained manner for 14 days which meets the objectives of the study. In a similar way to $C_{1}$, the $C_{2}$ exhibited a sustained release pattern which is again because of the presence of higher HPMC contents in the top layer, (HPMC is commonly used in sustained release formulations to prolong drug release). The maximum amount of drug release noted from $\mathrm{B}_{2}$ and $\mathrm{C}_{2}$ after day 14 is $87.91 \%$ and $83.13 \%$ respectively. These results show that the developed scaffolds have the potential to release the drugs for prolong period of time and should reduce the concurrent administration of the incorporated drugs during in vivo evaluation.

\section{Fig. 4}

Drug release profile of all four formulations containing simple blended drugs and enriched with drug loaded microspheres and nanofibers respectively (n $=3$ ) 


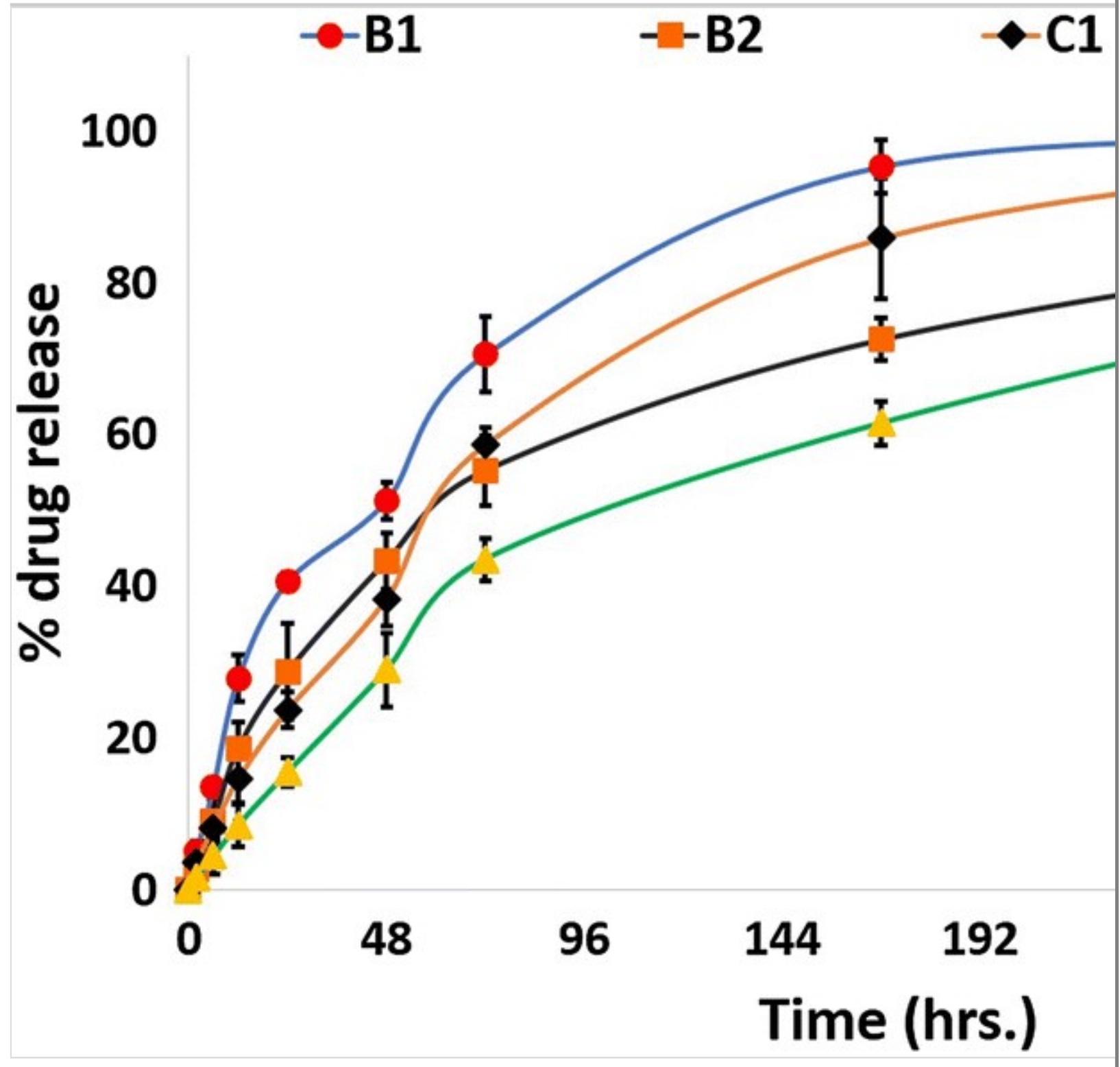

\section{Drug release kinetics}

The release data after fitting into various kinetic models is presented in Table 2. According to the data there is a linear relationship among the drug release and time, however, the best fit is found in Higuchi's rate equation with an $\mathrm{R}^{2}$ value of 0.983 which best elucidates the drug release from micro/nano drug delivery systems. As the regression value obtained from all formulations is higher than 0.45 (diffusion co-efficient) therefore following non-Fickian diffusion mechanism. This also shows that the drug release from matrices is not dependent on the concentration of drug. The 
data in tabulated form is presented in Table 2 (see also Figures S5-S9 in supplementary data sheet).

\section{Table 2}

Data showing in vitro release kinetics (analyzed by regression co-efficient method) frc

\begin{tabular}{|c|c|c|c|c|c|c|c|c|c|}
\hline \multirow{2}{*}{ Formulation } & \multicolumn{2}{|c|}{ Zero Order } & \multicolumn{2}{|c|}{ First order } & \multicolumn{2}{|c|}{ Higuchi } & \multicolumn{2}{|c|}{$\begin{array}{l}\text { Hixson } \\
\text { Crowell }\end{array}$} & \multirow{2}{*}{\begin{tabular}{|l|l}
$\mathbf{K}$ \\
$\mathbf{P}$ \\
$\mathbf{R}$
\end{tabular}} \\
\hline & $\mathbf{R}^{2}$ & $\mathbf{K}$ & $\mathbf{R}^{2}$ & $\mathbf{K}$ & $\mathbf{R}^{2}$ & $\mathbf{K}$ & $\mathbf{R}^{2}$ & $\mathbf{K}$ & \\
\hline $\mathrm{B}_{1}$ & 0.729 & 0.285 & 0.367 & 0.008 & 0.928 & 6.052 & 0.941 & -0.012 & 0 \\
\hline $\mathrm{B}_{2}$ & 0.797 & 0.251 & 0.417 & 0.008 & 0.963 & 5.204 & 0.920 & -0.006 & 0 \\
\hline $\mathrm{C}_{1}$ & 0.838 & 0.299 & 0.479 & 0.009 & 0.968 & 6.053 & 0.983 & -0.010 & 0 \\
\hline $\mathrm{C}_{2}$ & 0.893 & 0.249 & 0.534 & 0.010 & 0.983 & 4.928 & 0.967 & -0.006 & 0 \\
\hline
\end{tabular}

$A M$ anomalous (non Fickian) diffusion

\section{Cell culture}

Cell-substrate interactions are a crucial step for various cellular functions including motility, proliferation, differentiation and apoptosis. The biocompatible nature of a material is revealed by the initial adhesive response of the cell towards the biomaterial surface. Cell attachment, viability and proliferation of Mouse MC3T3-E1 pre-osteoblast cells on both layers of the scaffold was studied.

\section{Cell attachment assay}

To understand the biocompatible nature of the scaffolds, we analyzed these scaffolds for in vitro cell attachment studies using scanning electron microscopy after 3 days of incubation. For every cell, the first step is to adhere at the material surface and after attachment the protrusion of filopodia from the surface to communicate with the surrounding environment. From the SEM images shown in Fig. 5, it is evident that these scaffolds have biocompatible surface which supported the attachment and growth of MC3T3-E1 cells in both bottom and top layers. Cell 
adherence and cytoplasmic extensions can be seen in all samples as pointed by yellow arrows, and uniform layers of cells are evident even after 3 days of incubation. This also shows that cells are not only adhered to the surface of the scaffolds but have also proliferated inside the pores which are particularly evident in case of $\mathrm{C}_{\mathrm{o}}$ and $\mathrm{C}_{1}$. The formation of cells layers shows that the MC3T3-E1 cells have high affinity towards these scaffolds. These results are consistent with the results of other researchers (Akman et al. 2010; Niu et al. 2011). On the other hand, the presence of both drugs in $\mathrm{B}_{1}$ and $\mathrm{C}_{1}$ as well as in $\mathrm{B}_{2}$ and $\mathrm{C}_{2}$ didn't affected the cytocompatibility safety profile of the designed scaffolds. The appearance of microarchitecture inside the pore walls after degradation as shown by the blue arrows is also an additional benefit which provides greater surface area for the attachment and transport of cells inside the pore walls and allows the scaffold to be completely replaced with body tissue over time.

Fig. 5

Cell attachment of Mouse MC3T3-E1 pre-osteoblast cells on the scaffolds: bone control i.e. $\mathrm{B}_{\mathrm{o}}(\mathbf{a})$, cartilage control i.e. $\mathrm{C}_{\mathrm{o}}(\mathbf{b})$, TCN in bottom i.e. $\mathrm{B}_{1}$ (c), CFX in top i.e. $\mathrm{C}_{1}(\mathbf{d}), \mathrm{TCN} / \mathrm{MS}$ in bottom i.e. $\mathrm{B}_{2}(\mathbf{e}), \mathrm{CFX} / \mathrm{NFs}$ in top i.e. $\mathrm{C}_{2}(\mathbf{f})$ 

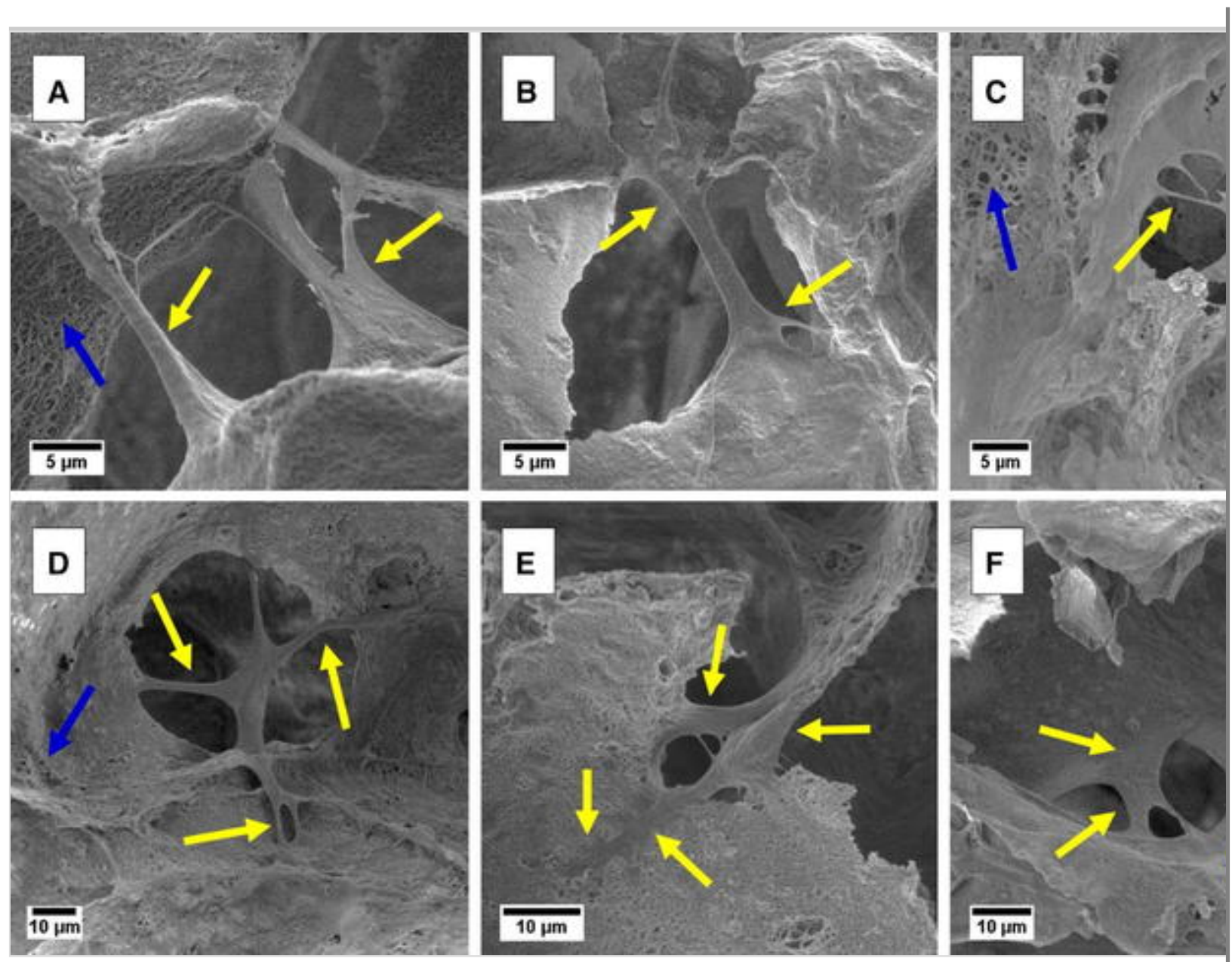

Cell migration assay

The results of the wound healing method are presented in Fig. 6. Images were recorded in the presence of materials along with a positive control. From the images it is evident that the cells were migrating from both edges to fill the gap with respect to time. Initially a $1 \mathrm{~mm}$ incision was made in the cells monolayer using a sterilized micropipette tip. The time zero image is shown in Fig. 6a. After incubation the cells started migration from both ends and covered almost $40 \%$ of the area in $4 \mathrm{~h}$ which reached up to $50 \%$ in $6 \mathrm{~h}$. In the graph it is seen that initially the migration was a bit slow up to $6 \mathrm{~h}$ and then becomes linear which is probably because of the cells adaptation to the new environment at the start of the assay. The cells covered about $75 \%$ of the gap by the end of $12 \mathrm{~h}$. The gap becomes totally confluent after about $15 \mathrm{~h}$ which is again a very good sign of the biocompatibility of the developed scaffolds. From these results it can be 
estimated that $15 \mathrm{~h}$ is the optimum time for MC3T3 Pre-osteoblast cells to migrate from one edge to the other and fill a gap of $1 \mathrm{~mm}$. When the regression co-efficient was applied it gave a linear relationship with $\mathrm{R}^{2}$ value of 0.971 which further endorsed the results. Figure 6 represents the results of $\mathrm{B}_{0}$.

Fig. 6

Cell migration assay: at time 0 (a), after $6 \mathrm{~h}(\mathbf{b})$, after $12 \mathrm{~h}(\mathbf{c})$. Graph showing the relationship between gap width and time $(n=3)$
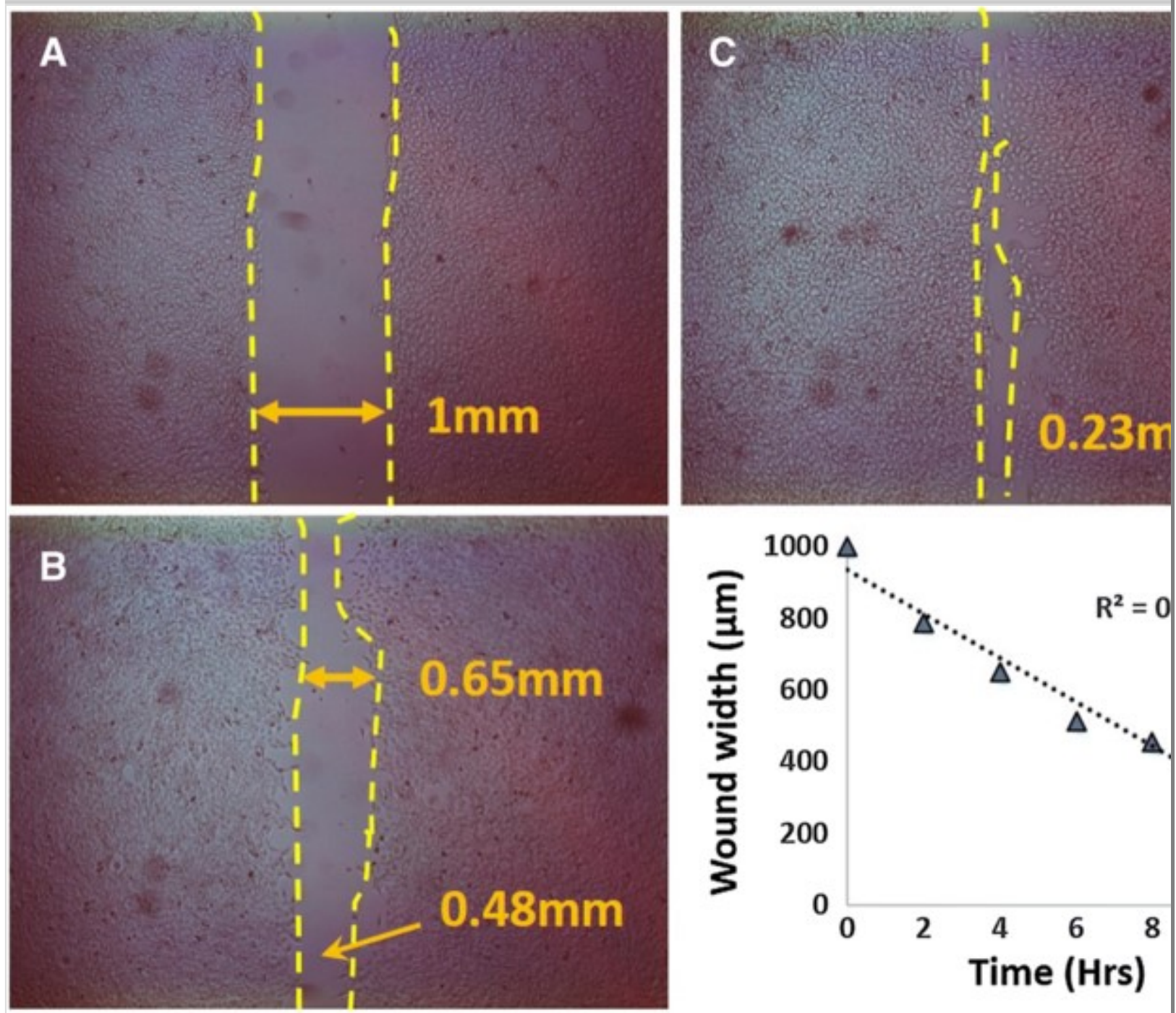

Cell viability and proliferation

Alamar blue assay 
Alamar blue cell proliferation assay in kinetic mode was used to check the cell viability. The results shown in Fig. 7 compares the cell's growth with respect to time for all formulations. Cells growth at day 2 was slower than control because it took some time for the cells to adopt themselves to the new environment, however, once the cells entered the exponential phase a marked increase in cells growth was observed (day 8) which is an indicator of the biocompatible nature of these scaffolds. This increase in fluorescence at day 8 confirmed that cells are metabolically active and started proliferation inside the pores of scaffolds. Similar results were previously reported by other researchers (Zhang et al. 2012; Koç et al. 2016). This also shows that the presence of both drugs has no effect towards cell viability as the drug release was continuous and its concentration increased with time. The same was reflected in cell attachment studies where the cell adherence to the surface and cytoplasmic extensions across the pore walls confirmed that these scaffolds are biocompatible.

Fig. 7

Alamar blue assay representing cell proliferation after 2 and 8 days of incubation $(\mathrm{n}=3)$ 


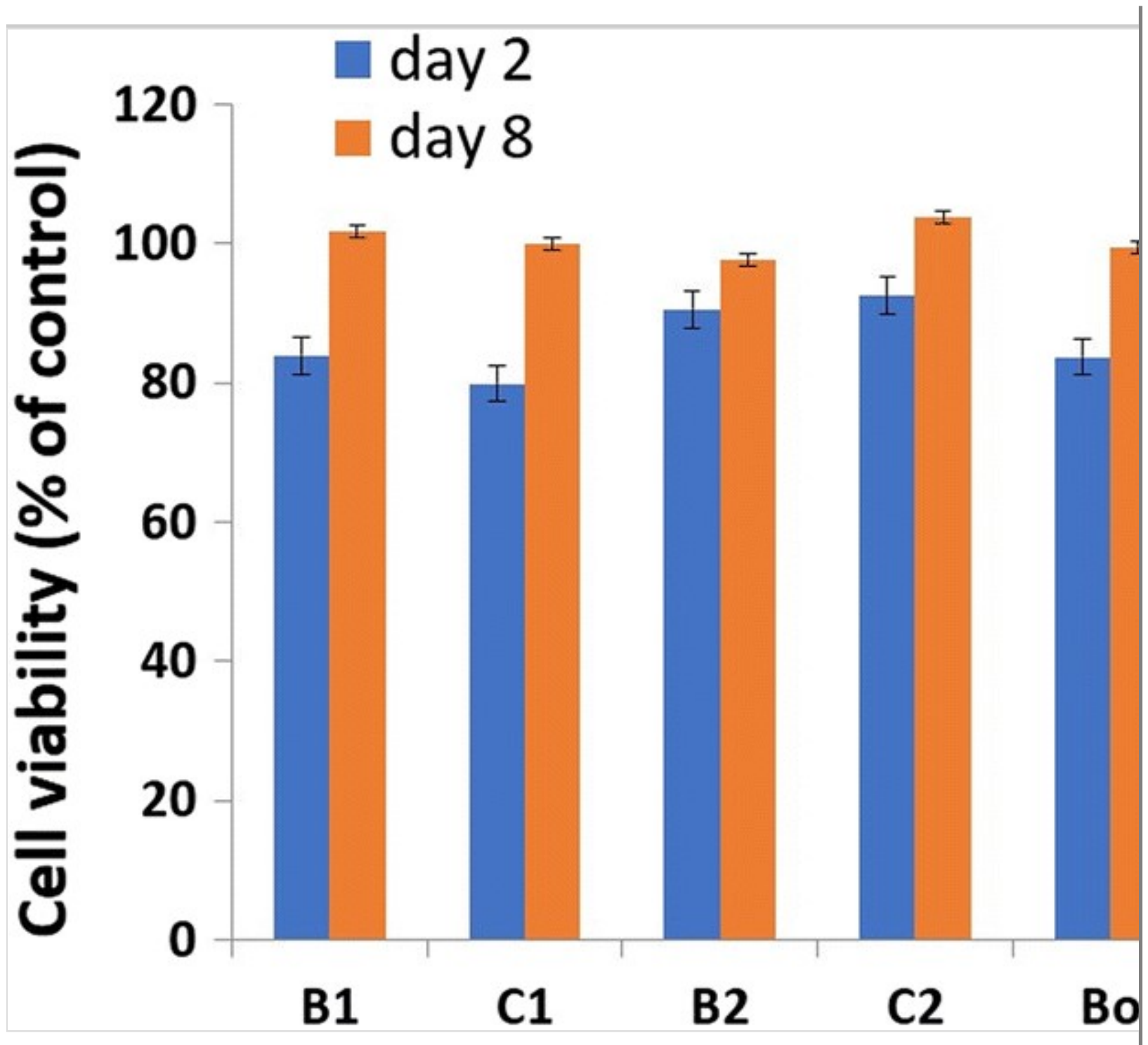

Live/dead assay and Nuclei staining

The live/dead staining was performed to determine cell viability after 3 days of incubation. The cells were visualized by fluorescence microscope where viable cells stained green and dead cells as red. Figure 8a shows that all samples contained sufficient number of viable cells. The images show cells spreading not only on the surface but the ingrowth inside the pores. These results show that the scaffolds have good cytocompatibility. This data also reinforces the results of alamar blue assay where the number of metabolically active cells exceeded than the control at the end of 8 days incubation. These results strongly suggest that the scaffolds have biocompatible surfaces and adequate porosity which facilitates cell 
attachment and proliferation. Nuclei staining (blue color) using DAPI was carried out further to confirm the attachment and alignment of MC3T3-E1 cell lines. DAPI staining showed that all the scaffolds were covered with cells and they proliferated inside the pores which depicts that with time these cells will find space to grow and replace the scaffold with native ECM Fig. 8b.

\section{Fig. 8}

a Live/dead assay of the prepared scaffolds, bone control; $\mathrm{B}_{\mathrm{o}}(\mathrm{A})$, cartilage control; $\mathrm{C}_{\mathrm{o}}(\mathrm{B}), \mathrm{TCN}$ in bottom; $\mathrm{B}_{1}(\mathrm{C}), \mathrm{CFX}$ in top; $\mathrm{C}_{1}(\mathrm{D}), \mathrm{TCN} / \mathrm{MS}$ in bottom; $B_{2}(E), C F X / N F s$ in top; $C_{2}(F)$ and $\mathbf{b}$ samples after DAPI staining, bone control; $\mathrm{B}_{\mathrm{o}}(\mathrm{A})$, cartilage control; $\mathrm{C}_{\mathrm{o}}(\mathrm{B}), \mathrm{TCN}$ in bottom; $\mathrm{B}_{1}(\mathrm{C}), \mathrm{CFX}$ in top; $\mathrm{C}_{1}(\mathrm{D})$, TCN/MS in bottom; $\mathrm{B}_{2}(\mathrm{E}), \mathrm{CFX} / \mathrm{NFs}$ in top; $\mathrm{C}_{2}(\mathrm{~F})$ 


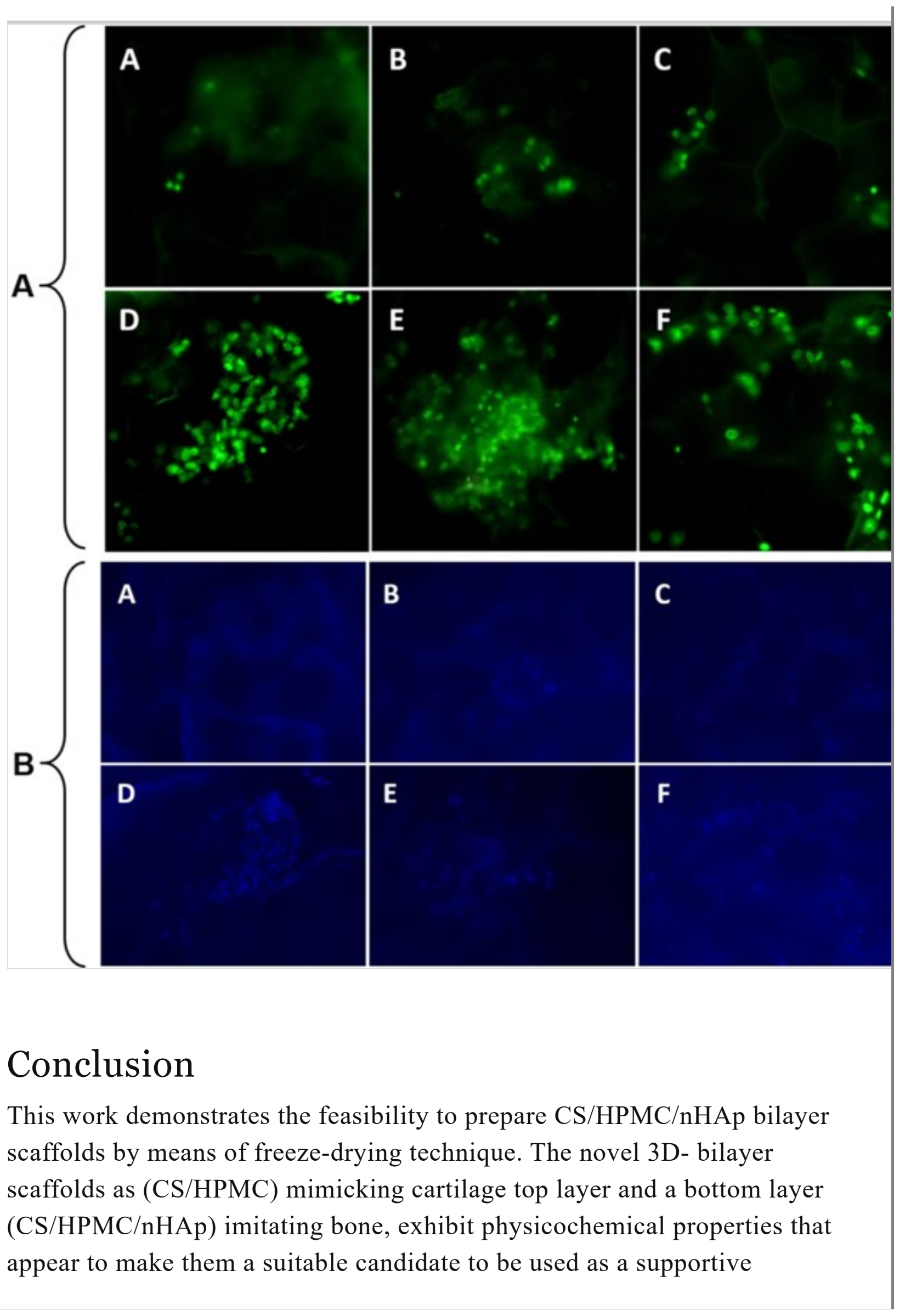


structure for cells functions. The combination of HPMC and chitosan in both layers resulted in sustained release profile for both drugs over a period of 7 days which positively supported our hypothesis. This was due to the presence of methoxy and hydroxypropyl groups in the structure of HPMC that strongly binds with chitosan (Khan et al. 2015). The addition of drugs in the form of microspheres and nanofibers was successful and they provided a prolonged drug release up to 14 days. The results of mechanical properties show that the scaffolds have good mechanical properties which remain the prime objective behind the designing of scaffold for load bearing areas. Moreover, the in vitro cell culture studies demonstrated that both HA and CS layers provide an adequate 3D support for the attachment, proliferation and differentiation of MC3T3-E1 into osteoblasts and chondrocytes, respectively. The CS/HPMC/nHAp based bilayer scaffolds are advantageous by several reasons, namely, they can be designed with several sizes and controlled architecture to fit patient specific injuries and cell functions, respectively. The CS/HPMC/nHAp bilayered scaffolds showed promising biological behavior and may therefore find applications in tissue engineering of bone and osteochondral defects however in vivo evaluation of these scaffolds is our next objective.

\section{Publisher's Note}

Springer Nature remains neutral with regard to jurisdictional claims in published maps and institutional affiliations.

\section{Acknowledgments}

We are thankful to the Higher education commission (HEC) Pakistan for providing the financial assistance for carrying out the research project under NRPU (Grant No. 4099).

\section{Electronic supplementary material}

Below is the link to the electronic supplementary material.

Supplementary material 1 (DOCX 1849 kb) 


\section{References}

Akman AC, Seda Tiğlı R, Gümüşderelioğlu M, Nohutcu RM (2010) Bone morphogenetic protein-6-loaded chitosan scaffolds enhance the osteoblastic characteristics of MC3T3-E1 cells. Artif Organs 34:65-74

Beşkardeş IG, Demirtaş TT, Durukan MD, Gümüşderelioğlu M (2015) Microwave-assisted fabrication of chitosan-hydroxyapatite superporous hydrogel composites as bone scaffolds. J Tissue Eng Regen Med 9:1233-1246

Bohaček I, Bojanić I, Gajović S, Josipović M, Jelić M (2015) Articular cartilage repair techniques exploiting intrinsic healing capacity-Which one is the best? Period Biologorum 117:125-133

Bouville F, Maire E, Deville S (2014) Lightweight and stiff cellular ceramic structures by ice templating. J Mater Res 29:175-181

Chen D, Shen J, Zhao W, Wang T, Han L, Hamilton JL et al (2017) Osteoarthritis: toward a comprehensive understanding of pathological mechanism. Bone Res 5:16044

Doran PM (2015) Cartilage tissue engineering: What have we learned in practice? In: Doran P (ed) Cartilage tissue engineering. Springer, New York

Falah M, Nierenberg G, Soudry M, Hayden M, Volpin G (2010) Treatment of articular cartilage lesions of the knee. Int Orthop 34:621630

García-Gareta E, Coathup MJ, Blunn GW (2015) Osteoinduction of bone grafting materials for bone repair and regeneration. Bone 81:112121 
Ghasemi-Mobarakeh L, Prabhakaran MP, Morshed M, Nasr-Esfahani M-H, Ramakrishna S (2008) Electrospun poly ( $\varepsilon$-caprolactone)/gelatin nanofibrous scaffolds for nerve tissue engineering. Biomaterials 29:4532-4539

Ghasemi-Mobarakeh L, Prabhakaran MP, Tian L, ShamirzaeiJeshvaghani E, Dehghani L, Ramakrishna S (2015) Structural properties of scaffolds: crucial parameters towards stem cells differentiation. World J Stem Cells 7:728-744

Gille J, Behrens P, Volpi P, De Girolamo L, Reiss E, Zoch W et al (2013) Outcome of autologous matrix induced chondrogenesis (AMIC) in cartilage knee surgery: data of the AMIC Registry. Arch Orthop Trauma Surg 133:87-93

Gobbi A, Karnatzikos G, Sankineani SR (2014) One-step surgery with multipotent stem cells for the treatment of large full-thickness chondral defects of the knee. Am J Sports Med 42:648-657

Huey DJ, Hu JC, Athanasiou KA (2012) Unlike bone, cartilage regeneration remains elusive. Science 338:917-921

Iqbal H, Ali M, Zeeshan R, Mutahir Z, Iqbal F, Nawaz MAH et al (2017) Chitosan/hydroxyapatite (HA)/hydroxypropylmethyl cellulose (HPMC) spongy scaffolds-synthesis and evaluation as potential alveolar bone substitutes. Colloids Surf B 160:553-563

Justus CR, Leffler N, Ruiz-Echevarria M, Yang LV (2014) In vitro cell migration and invasion assays. J Vis Exp JoVE 88:e51046 AQ2

Khan AF, Afzal A, Chaudhary AA, Saleem M, Shahzadi L, Jamal A et al (2015) (Hydroxypropyl) methylcellulose mediated synthesis of highly porous composite scaffolds for trabecular bone repair applications. Sci Adv Mater 7:1177-1186 
Koç A, Elçin AE, Elçin YM (2016) Ectopic osteogenic tissue formation by MC3T3-E1 cell-laden chitosan/hydroxyapatite composite scaffold. Artif Cells Nanomed Biotechnol 44:1440-1447

Kon E, Delcogliano M, Filardo G, Busacca M, Di Martino A, Marcacci M (2011) Novel nano-composite multilayered biomaterial for osteochondral regeneration: a pilot clinical trial. Am J Sports Med 39:1180-1190

Levingstone TJ, Matsiko A, Dickson GR, O’Brien FJ, Gleeson JP (2014) A biomimetic multi-layered collagen-based scaffold for osteochondral repair. Acta Biomater 10:1996-2004

Lu S, Lam J, Trachtenberg JE, Lee EJ, Seyednejad H, van den Beucken JJ et al (2014) Dual growth factor delivery from bilayered, biodegradable hydrogel composites for spatially-guided osteochondral tissue repair. Biomaterials 35:8829-8839

Martin I, Miot S, Barbero A, Jakob M, Wendt D (2007) Osteochondral tissue engineering. J Biomech 40:750-765

Niu X, Fan Y, Liu X, Li X, Li P, Wang J et al (2011) Repair of bone defect in femoral condyle using microencapsulated chitosan, nanohydroxyapatite/collagen and poly (L-lactide)-based microspherescaffold delivery system. Artif Organs 35:E119-E128

Nukavarapu SP, Dorcemus DL (2013) Osteochondral tissue engineering: current strategies and challenges. Biotechnol Adv 31:706721

Polo-Corrales L, Latorre-Esteves M, Ramirez-Vick JE (2014) Scaffold design for bone regeneration. J Nanosci Nanotechnol 14:15-56

Robinson JL, Moglia RS, Stuebben MC, McEnery MA, CosgriffHernandez E (2014) Achieving interconnected pore architecture in 
injectable polyHIPEs for bone tissue engineering. Tissue Eng Part A 20:1103-1112

Ruiz-Cantu L, Gleadall A, Faris C, Segal J, Shakesheff K, Yang J (2016) Characterisation of the surface structure of 3D printed scaffolds for cell infiltration and surgical suturing. Biofabrication 8:015016

Sannino A, Demitri C, Madaghiele M (2009) Biodegradable cellulosebased hydrogels: design and applications. Materials 2:353-373

Seo S-S, Kim C-W, Jung D-W (2011) Management of focal chondral lesion in the knee joint. Knee Surg Relat Res 23:185

Sridharan B, Mohan N, Berkland CJ, Detamore MS (2016) Material characterization of microsphere-based scaffolds with encapsulated raw materials. Mater Sci Eng C 63:422-428

Uswatta SP, Okeke IU, Jayasuriya AC (2016) Injectable porous nanohydroxyapatite/chitosan/tripolyphosphate scaffolds with improved compressive strength for bone regeneration. Mater Sci Eng C 69:505512

Whited BM, Whitney JR, Hofmann MC, Xu Y, Rylander MN (2011) Pre-osteoblast infiltration and differentiation in highly porous apatitecoated PLLA electrospun scaffolds. Biomaterials 32:2294-2304

Yan LP, Oliveira JM, Oliveira AL, Reis RL (2014) Silk fibroin/nano$\mathrm{CaP}$ bilayered scaffolds for osteochondral tissue engineering. Key Eng Mater 587:245-248

Yan L-P, Silva-Correia J, Oliveira MB, Vilela C, Pereira H, Sousa RA et al (2015) Bilayered silk/silk-nanoCaP scaffolds for osteochondral tissue engineering: in vitro and in vivo assessment of biological performance. Acta Biomater 12:227-241 
Yang PJ, Temenoff JS (2009) Engineering orthopedic tissue interfaces. Tissue Eng Part B Rev 15:127-141

Zhang J, Wang C, Wang J, Qu Y, Liu G (2012) In vivo drug release and antibacterial properties of vancomycin loaded hydroxyapatite/chitosan composite. Drug Deliv 19:264-269 